\title{
A Atuação do Psicólogo no SUS: Análise de Alguns Impasses
}

The Practice of the Psychologist at SUS:

An Analysis of Some Impasses

La Actuación del Psicólogo en el SUS:

Análisis de Algunos Impases

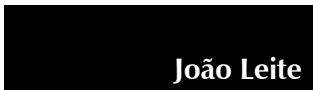

Ferreira Neto

Pontifícia

Universidade Católica de Minas Gerais
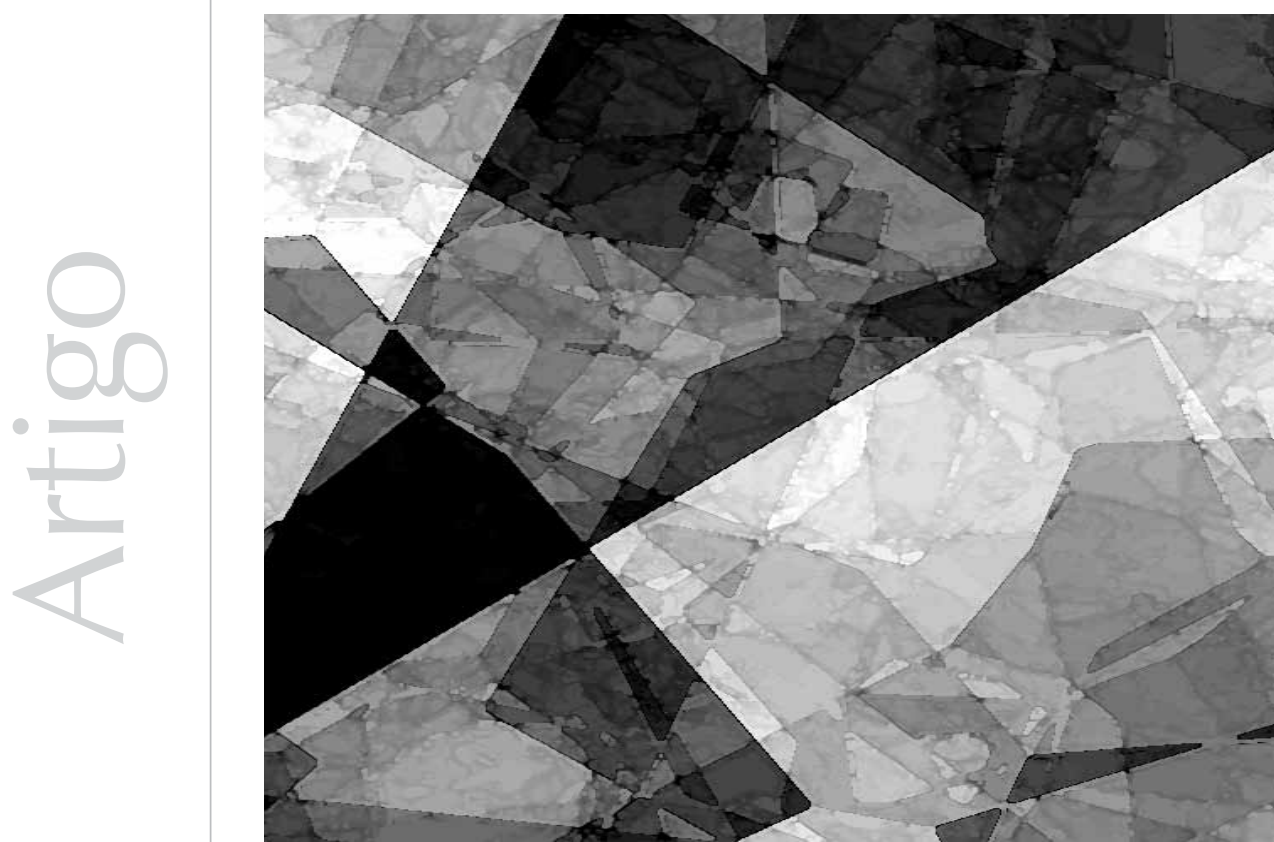
Resumo: Este estudo discute alguns impasses atuais vividos pelo psicólogo no Sistema Único de Saúde SUS. Sua hipótese é de que eles foram produzidos por dois fatores: (1) a porta de entrada dos psicólogos no SUS associada à reforma psiquiátrica; (2) o modelo prevalente de formação nos cursos de graduação que privilegiam a clínica privada. Esses fatores geraram ações profissionais que tendiam a reforçar um modelo de identidade profissional clássico centrado no atendimento individual, em detrimento de uma atuação mais inventiva no campo da saúde. Foi realizada uma discussão a partir da literatura que aborda essas questões. A apresentação de elementos da história do programa de saúde mental em Belo Horizonte serviu como campo particularizado de ilustração e de contraposição a alguns tópicos encontrados na revisão bibliográfica. O artigo realça a importância da ampliação da ação dos psicólogos nas equipes de saúde mental para além da clínica, sem, entretanto, desprezar sua relevância, e salienta a parceria com o Programa de Saúde da Família nesse processo.

Palavras-chave: Saúde mental. SUS. Formação do psicólogo. Saúde da família.

\begin{abstract}
This study discusses some current impasses experienced by psychologists who work for the Sistema Único de Saúde (SUS), the Brazilian public health system. Its hypothesis is that they were produced by two factors: (1) the admission of psychologists into the SUS was associated to the psychiatric reform; (2) the prevailing model of training in undergraduation courses privileged the private clinic. Those factors produced professional practices that tended to reinforce a classic professional identity model centred on the individual clinic, in detriment of a more inventive practice in the health field. It was proposed a discussion based on the literature that approaches these issues. The presentation of elements of the history of the Mental Health Programme in Belo Horizonte was used as a particular field for illustration and counterpoint of some issues approached in the bibliographic review. The article highlights the importance of the widening of psychologists' practices on the health teams going further than the clinical practice, even though regarding its relevance and underlines the partnership with the Family Health Program in this process.
\end{abstract}

Keywords: Mental health. SUS. Psychology training. Family health.

Resumen: Este estudio discute algunos impases actuales vividos por el psicólogo en el Sistema Único de Salud - SUS. Su hipótesis es de que éstos fueron producidos por dos factores: (1) la puerta de entrada de los psicólogos en el SUS asociada a la reforma psiquiátrica; (2) el modelo prevalente de formación en los cursos de graduación que privilegian la clínica privada. Esos factores generaron acciones profesionales que tendían a reforzar un modelo de identidad profesional clásico centrado en el atendimiento individual, en detrimento de una actuación más inventiva en el campo de la salud. Fue realizada una discusión a partir de la literatura que aborda esas cuestiones. La presentación de elementos de la historia del programa de salud mental en Belo Horizonte sirvió como campo particularizado de ilustración y de contraposición a algunos tópicos encontrados en la revisión bibliográfica. El artículo realza la importancia de la ampliación de la acción de los psicólogos en los equipos de salud mental para más allá de la clínica, sin, no obstante, despreciar su relevancia, y resalta la aparcería con el Programa de Salud de la Familia en ese proceso.

Palabras clave: Salud mental. SUS. Formación del psicólogo. Salud de la familia.

Diversos estudos revelam que a presença crescente dos psicólogos na saúde pública no Brasil aconteceu em associação com a reforma psiquiátrica, com a criação do campo chamado da saúde mental (Dimenstein, 1998; Ferreira Neto, 2004; Lo Bianco, Bastos, Nunes, \& Silva, 1994; Silva, 1992). Para Dimenstein (1998), ainda que em relação aos médicos, maior força de trabalho de graduação superior na saúde, o contingente de psicólogos seja ainda pequeno, "pode-se notar que, de 1976 a 1984, os empregos em Psicologia no setor saúde experimentaram uma taxa de crescimento muito acima da média das outras categorias profissionais, chegando a atingir $21,47 \%$, só ocorrendo o mesmo fato com os sanitaristas $(21,65 \%)^{\prime \prime}$ (p. 56). Dados recentes contabilizam 14.407 psicólogos trabalhando no Sistema Único de Saúde - SUS, o que corresponde a 10\% dos psicólogos registrados no Sistema Conselhos de Psicologia (Spink, 2007).

Como esse crescimento ocorreu no contexto da crítica ao modelo asilar com a criação do programa de saúde mental, por vezes a 
reflexão sobre a atuação do psicólogo na saúde fica reduzida ao campo da saúde mental. Nossa hipótese é que essa porta de entrada na saúde pública, associada ao modelo prevalente de formação nos cursos de graduação, acarretou, como veremos adiante, alguns impasses na atuação do psicólogo na saúde. Interessa a este trabalho discutir, através de revisão da literatura, alguns dos atuais impasses da atuação do psicólogo no SUS, notadamente em dois aspectos: o da relação da saúde mental com o conjunto da saúde pública e o da construção da identidade/perfil do psicólogo na saúde no contexto de sua formação. A apresentação de elementos da história do Programa de Saúde Mental na cidade de Belo Horizonte, através da análise de alguns documentos centrais, servirá como um campo particularizado de ilustração e como contraposição a alguns elementos encontrados na revisão bibliográfica.

\section{Reforma sanitária e reforma psiquiátrica}

Vale indicar alguns aspectos históricos das políticas públicas de saúde entre o final dos anos 1970 e durante a década de 1980, especialmente no que tange à conexão entre os movimentos reforma sanitária reforma psiquiátrica. O movimento de reforma sanitária se consolidou nos anos 70 como um dos vários movimentos sociais que faziam frente ao regime militar na luta pela democratização do País. Amarante (1998) aponta como início do movimento de reforma psiquiátrica o ano 1978, a partir da crise da DINSAM (Divisão Nacional de Saúde Mental - MS), quando uma onda crítica foi deflagrada no Rio de Janeiro em relação aos desmandos que ocorriam nos hospitais psiquiátricos públicos da cidade, e que repercutiu por todo o País, desencadeando o surgimento do Movimento dos Trabalhadores em Saúde Mental (MTSM). Esse movimento, de base paraestatal, tinha ligações com as diversas experiências internacionais, tais como a norte-americana e as européias - prevenção, comunidades terapêuticas, psicoterapia institucional e de setor, psiquiatria democrática - e com o Movimento Nacional de Reforma Sanitária.

É importante observar que a relação entre as duas reformas, a psiquiátrica e a sanitária, caminhou entre momentos de conjunção e de disjunção. Inicialmente, sua origem é disjunta, mas a década de 80 marcou uma primeira conjunção a partir da "tática desenvolvida inicialmente no seio do movimento sanitário, de ocupação de espaços públicos de poder e de tomada de decisão como forma de introduzir mudanças no sistema de saúde" (Amarante, 1998, p. 91). A chamada Nova República tornou-se o apogeu dessa tática de ocupação, quando o movimento sanitário, junto ao da reforma psiquiátrica, se confundiu com o próprio Estado.

O ano 1987 evidenciou uma nova disjunção entre os dois movimentos balizada pela I Conferência Nacional de Saúde Mental, e especialmente pelo II Encontro Nacional dos Trabalhadores em Saúde Mental, em Bauru. Nesse Encontro, foi produzida a consigna por uma sociedade sem manicômios e instituído o dia 18 de maio como o Dia Nacional da Luta Antimanicomial. A maioria dos trabalhadores presentes eram profissionais não médicos, grande parte, psicólogos. Contando com a participação de intelectuais de diversas áreas, elaborou-se uma pauta de conceitos para instrumentalizar a luta pela reforma psiquiátrica, visando à autonomia do movimento em relação ao Estado. As diretrizes apontavam um caminho de alargamento das fronteiras da luta para uma ação no interior da própria cultura, trazendo a discussão sobre a loucura para o cotidiano da sociedade, em uma estratégia que ampliava a atividade puramente assistencial e criava pontes entre as ações no âmbito do Estado com a sociedade 
civil (Bezerra Jr., 1994). Prevaleceu, desde então, um ideário de "desinstitucionalização ou da desconstrução/invenção" (Amarante, 1998, p. 93), induzindo a uma disjunção com o movimento sanitarista em sua tática de ocupação da máquina estatal. Desde essa nova direção, seriam visadas alianças com a sociedade civil e com os movimentos populares e com as associações de usuários e de familiares, a busca da rua, da imprensa, da opinião pública.

Vale ainda mencionar que a reforma psiquiátrica "assumiu repercussão nacional" com a intervenção da Secretaria Municipal de Saúde de Santos na Casa de Saúde Anchieta, e a subsequente criação de dispositivos antimanicomiais na cidade, em gestão que inspirou várias experiências posteriormente conduzidas por todo o País (Amarante, 1998, p. 83).

A atual conjunção entre as reformas se deu com a transformação em leis das propostas do movimento, iniciadas em nível estadual e que culminaram com a promulgação da Lei federal no 10.216/2001, proposta pelo Deputado Federal Paulo Delgado (PT - MG) (Furtado \& Onocko Campos, 2005). Podemos acrescentar a isso outro acontecimento político, o fato de, progressivamente, o Partido dos Trabalhadores, onde se originou o primeiro projeto de reforma psiquiátrica, ter conquistado várias prefeituras em cidades importantes, e, em 2002, o governo federal. Essa conjunção foi incrementada pela recente ampliação, em nível nacional, do Programa de Saúde da Família (PSF), visando a reorientar o modelo assistencial do SUS em todos os níveis, com marcada ênfase na atenção básica (Brasil, 2004a). A progressiva implementação desse programa tem operado mudanças em todo o SUS, inclusive na organização do processo de trabalho em saúde mental, que passa a ser responsável pelo "apoio matricial às equipes da atenção básica", através de constantes parcerias de trabalho conjunto de cor-responsabilização pela clientela em comum (Brasil, 2004b), como veremos na análise específica da experiência de Belo Horizonte.

Vemos, por conseguinte, na história nacional da reforma psiquiátrica, sua disjunção e conjunção com o movimento da reforma sanitária. Essa trajetória pendular de distanciamento e aproximação entre a saúde mental e a saúde pública reverberou, como veremos adiante, nas experiências municipais de organização dos serviços e na atuação dos profissionais.

\section{Impasses entre formação e atuação}

Vários estudos têm sido feitos sobre a tradição de décadas de ensino em Psicologia voltado para o exercício autônomo e liberal da profissão em consultórios particulares (Ferreira Neto, 2004; Lo Bianco et al., 1994; Silva, 1992; Spink, 2003). Essa tradição da formação dos psicólogos foi absoluta até meados da década de 90, produzindo efeitos que até hoje se fazem sentir. Um deles é o da identificação do perfil do psicólogo com o de um profissional que atua na clínica.

O extenso debate em torno das Diretrizes Curriculares do Curso de Psicologia e sua aprovação final sinalizaram a mudança dos currículos, no quesito clínica, em duas direções. A primeira, na busca de um equilíbrio maior entre a chamada área clínica e as outras áreas de atuação do psicólogo; a segunda, na formulação de uma nova compreensão de clínica, não mais centrada na do modelo clássico de consultório privado, mas portando uma compreensão ampliada do campo, com destaque para a preocupação sobre o "contexto social" da prática clínica (Lo Bianco, 1994, p. 12). A experiência dos psicólogos a partir da década de 80 na saúde pública trouxe elementos importantes para o 
início da desconstrução do modelo anterior, ainda que essa virada ainda não se tenha feito de modo definitivo.

Desde o final da década de 70, vários estudos já alertavam para os problemas que a identidade não problematizada de psicólogo-psicoterapeuta produz nas diversas áreas de atuação do psicólogo. Dimenstein (2001) avalia, a partir de pesquisa com psicólogos na rede pública na cidade de Teresina, Pl, que o compromisso, para os entrevistados, "restringe-se ao cumprimento de tarefas que consolidam o modelo de identidade clássico" (p. 62), ou seja, a atuação como psicoterapeuta. Segundo a autora, os psicólogos ainda não realizaram uma efetiva revisão dos pressupostos teóricos e metodológicos para atuação na saúde, mantendo uma relação em que predomina a reprodução de saberes/ fazeres, em detrimento de sua produção. Confirma essa tendência a já mencionada pesquisa nacional de 2006, que, em seu eixo qualitativo, indica que $80 \%$ dos psicólogos entrevistados descrevem suas atividades como essencialmente de atendimento direto ao usuário, negligenciando mencionar as variadas ações "necessárias para a plena realização dessa tarefa" (Spink, 2007, p. 84), como se não reconhecessem como trabalho o que não estivesse diretamente associado à sua imagem de psicoterapeutas.

Lima (2005), em pesquisa realizada em Salvador, onde a inserção dos psicólogos na rede pública se deu mais tardiamente que em outros Estados brasileiros, salienta o peso da identidade profissional "psicanalista" como fator inibidor de práticas profissionais que rompam com o modelo clássico de clínica. Lá, como em outros lugares, houve uma "forte influência da psicanálise como visão de mundo, que orienta as práticas psicológicas desenvolvidas pela maioria dos profissionais", o que traz como referência para sua atuação o fato de serem "mais ou menos psicanalistas do que o são em seus consultórios particulares" (p. 433). A autora considera que os profissionais ficam reféns do "preconceito tecnológico", apresentando dificuldade de desenvolver ações que ultrapassassem o repertório preconizado pela própria formação. Uma profissional entrevistada se descreve "ociosa", em decorrência do fato de a clientela que buscava o serviço não permanecer no tratamento psicanalítico oferecido. Mesmo assim, a psicóloga resistia na manutenção de sua oferta de tratamento, sem problematizar a ausência da demanda na unidade. A pesquisadora apresenta, como contraponto a esse quadro, outra profissional que se envolve no que chama de "atuação psicológica coletiva", através de práticas pedagógicas, de atendimento individual e de trabalho de grupo, relativas à problemática DST, HIV e AIDS. Segundo a autora, a profissional se formou mais recentemente, em 2001, tendo tido contato com professores "que têm uma relação mais crítica sobre a formação de psicólogo" (Lima, 2005, p. 436), o que the permitiu desenvolver uma atuação mais criativa e mais próxima das necessidades da unidade de saúde onde trabalhava.

Vale salientar que a fragilidade da organização do programa de saúde mental em Salvador descrito pela autora permitia uma situação de ociosidade dos profissionais face ao atendimento dos pacientes graves. Como veremos adiante, diferentemente de Salvador, a análise do programa em Belo Horizonte, já consolidado, repercute no trabalho dos profissionais através de uma situação de sobrecarga na atenção ao portador de sofrimento mental, permitindo assim uma escassa margem de manobra na oferta de outros serviços assistenciais.

Em outro trabalho, Spink (2003) discute alguns dos impactos dos psicólogos ao saírem "da relação protegida, forjada na clínica particular - onde as normas são definidas 
pelo próprio psicólogo - e enfrentar a rede complexa de normas institucionais" (p. 137). O autor discorre sobre as possibilidades de trabalho nesse contexto: trabalhar o conjunto da instituição e trabalhar com o paciente, cliente da instituição. Segundo a autora, essa segunda alternativa tem sido a mais comum, negligenciando-se a expansão tanto do referencial contextual, na maior compreensão da dinâmica social e institucional do trabalho, quanto do próprio referencial teórico.

É interessante apontar algumas das diferenças entre as práticas desenvolvidas em consultórios particulares e as desenvolvidas na saúde pública, a partir da análise de um conjunto de novos encontros promovidos pela entrada dos psicólogos no SUS.

O primeiro deles se dá com uma nova clientela até então distante da Psicologia clínica, oriunda das classes populares. As práticas clínicas, até então, foram "direcionadas aos padrões de classe média, que tem servido de base para padronização de seus instrumentos, métodos e técnicas, linguagens e valores em geral" (Silva, 1992, p. 32). Temos, portanto, uma situação de endogamia social, na qual terapeuta e paciente oriundos da mesma classe social permanecem cegos para as determinações sociais de tal prática. $\mathrm{O}$ encontro com essa clientela inédita, vinda dos segmentos mais pobres da população, promoveu novos questionamentos e impôs alterações tanto na atuação quanto na formação dos psicólogos.

O segundo foi o encontro com a condição de trabalho assalariado estatal e as vicissitudes que isso acarreta, em termos de regulação, horário de trabalho, hierarquias, prestação de contas, avaliação de produtividade, etc. Aqui vale a pena lembrar que os psicólogos, junto a outros profissionais, ainda que estejam inseridos em uma relação de suposta igualdade nas equipes multiprofissionais, vivem "na condição de subalternidade na hierarquia interna do campo, dominada pela categoria médica" (Dimenstein, 2001, p. 61). Isso pode ser comprovado tanto na organização do processo de trabalho quanto na diferença de remuneração das categorias.

Finalmente, há o encontro com outros saberes/ fazeres mais antigos na saúde pública, cujo trabalho estabelece uma interdependência com a qual o psicólogo, até então senhor de si numa atuação solitária, não estava acostumado a conviver, e para a qual sua formação anterior pouco contribuiu.

Essas são algumas das razões pelas quais a reprodução do modelo privado de atendimento, até então prática tão frequente na área da saúde, começou a se tornar insustentável, demandando o desenvolvimento de uma articulação necessária entre a prática clínica e o contexto mais ampliado da saúde coletiva.

\section{A experiência de Belo Horizonte}

O Programa de Saúde Mental foi oficialmente implantado em Minas Gerais, na Região Metropolitana de Belo Horizonte, em 1984, durante a gestão do governador Tancredo Neves, pelo PMDB. Nesse período, um número expressivo de profissionais de saúde com perfil progressista ocupou postos importantes na Secretaria Estadual de Saúde. Anteriormente a essa data, houve o Programa Integrado de Saúde Mental (PISAM), que teve curta duração, entre 1977 e 1979, e grupos de profissionais que atendiam em unidades básicas de saúde (centros de saúde) sem ligação com um projeto ou programa que organizasse as ações em saúde mental (Mendonça Filho \& Alkimin, 1998).

No Programa de Ações da Saúde Mental da Região Metropolitana (Secretaria Estadual de Saúde, 1985), início oficial do Programa 
na Região Metropolitana de Belo Horizonte (anterior à municipalização da saúde), 23 equipes foram estabelecidas na condição de referência secundária, ou seja, como "atendimento especializado", conforme definição da época. A princípio, os programas de saúde mental buscavam formular, de modo ainda primário, uma concepção integral de saúde - o famoso trinômio do biopsicossocial. Por isso, as primeiras equipes de saúde mental respeitavam essa conformação: psiquiatra (bio), psicólogo (psico) e assistente social (social). A falta de maior experiência para uma formulação mais sofisticada do que seria um trabalho em equipe multiprofissional e interdisciplinar conduziu a essa opção por uma alternativa mais óbvia.

Sua atuação teria seis eixos: atendimento à demanda específica (doença mental), apoio aos demais programas dos centros de saúde "integrando a saúde mental no contexto global da saúde" apoio técnico ao nível primário, articulação com os recursos das comunidades (escolas, creches, hospitais, associações de bairro), atendimento à criança e avaliação periódica do Programa. Apenas no primeiro eixo é mencionada a "necessidade de uma atenção especial aos egressos". Finalmente, as equipes foram formadas para um trabalho de "integração" com os hospitais psiquiátricos, no sentido de evitar "internações desnecessárias" (Secretaria Estadual de Saúde, 1985, p. 7). Não se falava ainda em substituição do modelo hospitalar.

A formação dos recursos humanos é abordada no documento como item fundamental do Programa, visando a garantir profissionais aptos para a implementação da proposta. A ênfase é pela formação em serviço: "a formação desses profissionais passa por uma prática desenvolvida em equipe e uma constante reflexão crítica dessa prática através de encontros, discussões e debates"
(Secretaria Estadual de Saúde, 1985, p. 16). A formação é considerada, para as equipes de saúde mental e para as equipes de saúde no nível primário, "com o objetivo de discutir amplamente as questões de saúde mental e as alternativas de trabalho". O Programa antecipava, portanto, o movimento que só seria efetivado décadas depois com o apoio matricial ao PSF, e propunha a integração da saúde mental com a saúde geral.

Somente durante a gestão municipal do prefeito Patrus Ananias - PT (93-96) a Secretaria de Municipal de Saúde de BH definiu e conduziu suas ações para priorizar, essencialmente, a assistência aos pacientes graves, impedindo assim que as agendas dos profissionais ficassem comprometidas e congestionadas com a inesgotável demanda espontânea ou o encaminhamento de crianças com dificuldade escolar, pacientes neuróticos comuns e aqueles pertencentes à "clientela cativa" dos Centros de Saúde. Nessa gestão, foi nomeado para a Secretaria Municipal de Saúde o psiquiatra César Campos, engajado, já de longa data, com os movimentos de luta contra o aparato asilar, e, nesse período, foram construídos os primeiros Centros de Convivência e os Centros de Referência em Saúde Mental - CERSAM (versão mineira dos Centros de Atenção Psicossocial - CAPS), dispositivos substitutivos ao hospital. Dois documentos-chave serão analisados visando à compreensão das particularidades da experiência mineira, o primeiro datado de 1998 (um balanço final da gestão), e o segundo, de 2003 (sobre a integração com o Programa de Saúde da Família).

O primeiro documento que avalia esse período foi publicado em uma coletânea escrita por técnicos, com a assessoria do professor Emerson Merhy, sobre a gestão da saúde. O capítulo que nos interessa é assinado pela coordenadora do Fórum Mineiro de Saúde Mental e pela própria 
coordenadora municipal de saúde mental (Lobosque \& Abou-Yd, 1998). Com o título A cidade e a loucura - entrelaces, o projeto de saúde mental é apresentado em uma versão marcadamente antimanicomial, cuja perspectiva é "a extinção do hospital psiquiátrico" e sua substituição por outro modelo de atenção (p. 244).

O texto, que possui uma função de relatório da gestão, porta um marcado tom político de ruptura com o que se fazia anteriormente. Essa ruptura é afirmada em pelo menos quatro aspectos. O primeiro deles, de cunho mais ideológico-organizacional, era a postulação de uma incompatibilidade com certa "vertente do movimento sanitário" com seu acento nos cuidados primários, "em detrimento do tratamento das doenças". Segundo as autoras, esse modelo sanitarista, considerado autoritário, estabelece uma divisão indesejada - "nos hospícios, os loucos; nos centros de saúde, os pequenos desviantes - crianças ditas problemáticas, mulheres ditas deprimidas - e as práticas preventivistas em geral" (p. 245). O projeto propõe o abandono do modelo americano de psiquiatria comunitária, adotado anteriormente pelo Programa da Região Metropolitana de 1985, com seus níveis primário (rede básica), secundário (serviços especializados) e terciário (hospital), pois ele valida a permanência do hospital no topo do modelo assistencial, por isso afirma que os CERSAM "não se caracterizam como serviços intermediários ou secundários" (p. 252), mas compõem uma rede de assistência que visa a substituir os hospitais psiquiátricos, sem hierarquizar os níveis de atenção.

O segundo tem componentes de gestão de pessoal, uma vez que a coordenação encontrou certa "oposição por parte de profissionais de saúde mental", que se mostravam resistentes "a assumir as novas diretrizes do trabalho" (Lobosque \& Abou-
Yd, 1998, p. 253). A proposta aponta uma mudança do foco da atenção das "crianças robustas e gestantes saudáveis", considerados clientela majoritária das unidades básicas, para os psicóticos e neuróticos graves, que passam a ser qualificados como "prioridades assistenciais" (p. 247). Isso acarretou, por parte da gestão, uma ação de desestímulo ao atendimento dos casos considerados mais leves bem como a participação em grupos de outros programas, como aqueles voltados para "gestantes ou diabéticos" ( $p$. 246). O tom depreciativo de avaliação do trabalho em grupos e da participação em outros programas de promoção da saúde, sem dúvida questionável, deve ser entendido a partir do contexto de uma gestão que se compromete com o objetivo antimanicomial da saúde mental.

O terceiro aspecto, de caráter políticoadministrativo, se revelou um passo fundamental para garantir a reorganização da assistência a partir das diretrizes antimanicomiais: a nova relação estabelecida da Secretaria Municipal da Saúde - SMS com os hospitais psiquiátricos. Isso envolveu a gestão dos hospitais privados conveniados por parte da Secretaria. Nesse sentido, foram realizadas várias ações visando a efetivar a desmontagem do "aparato manicomial": supervisão hospitalar efetiva nos hospitais privados conveniados ao SUS, proibição de novas internações fora dos dois hospitais públicos e disponibilização de todos os leitos hospitalares privados conveniados na Central de Internação municipal. Uma das medidas mais eficazes para a organização da nova rede de assistência em saúde mental foi o procedimento de garantir a cada paciente, antes de sua alta hospitalar, o agendamento de consulta, via Distritos Sanitários, com um profissional de saúde mental no centro de saúde mais próximo de sua residência. A organização desse fluxo impediu que os pacientes em alta ficassem sem atendimento 
ambulatorial e fossem reinternados após nova crise, e garantiu também a chegada dos egressos nas unidades básicas de saúde, rompendo o circuito alta-residência-crisenova internação. Pacientes e familiares passaram a conhecer uma nova possibilidade de atenção profissional, próxima de casa. Vale acentuar que, para romper o circuito hospitalar, não é suficiente a implantação de equipes nas unidades - é necessária uma política de organização do fluxo da demanda, caso contrário, os profissionais têm sua atividade drenada com a clientela cativa do serviço, sem que os egressos façam parte de sua clientela habitual.

O quarto aspecto, de caráter ético-técnico, diz respeito à concepção de clínica que subsidia um projeto antimanicomial. De um lado, existe o destaque à psicanálise: "sem a psicanálise, ...sem a referência que nos inspira, nossas práticas de pensamento e de trabalho não seriam o que são" (Lobosque \& Abou-Yd, 1998, p. 249). As autoras reconhecem que a psicanálise usualmente não está presente em momentos políticos incisivos, sendo, portanto, essa uma "rara articulação". Ainda é necessário se fazer uma análise mais acurada dos limites e das dificuldades oriundos da hegemonia da psicanálise no campo da saúde mental.

De qualquer modo, a contribuição da psicanálise isoladamente não é suficiente para se avaliar a atuação na saúde pública. Permanece a dificuldade presente no despreparo para conduzir uma clínica sem setting definido. Faz-se, então, necessário desfazer sua colagem com a clínica de consultório, uma vez que os espaços da primeira são múltiplos - abordagem de um paciente morador de rua, visita domiciliar, etc. Isso não se apresenta como tarefa simples, uma vez que a formação prevalente ainda atende a esse modelo. As autoras reconhecem que os profissionais não receberam anteriormente esse tipo de formação, e perguntam: "quem a recebe, aliás?!" (p. 263).

O texto aborda também duas importantes ações extraclínicas desenvolvidas pela saúde mental junto à demanda infantil. A primeira foi a criação de fóruns regionais de atenção à saúde mental da criança e do adolescente, envolvendo variados segmentos, tais como os técnicos de saúde mental e da educação, membros de Conselhos Tutelares e de outras instâncias comunitárias, com o objetivo de criar espaços de diálogo e busca de soluções na atenção à infância tanto individual quanto coletivamente; o segundo foi o projeto Arte na Saúde, como estratégia de não psicologizar as dificuldades infantis, utilizando espaços comunitários com monitores da própria comunidade e desenvolvendo atividades com crianças idealizadas por uma psicóloga de unidade básica.

\section{Saúde mental e a estratégia saúde da família}

O segundo documento municipal a ser analisado neste artigo, datado de 02/07/2003, é intitulado Saúde Mental na Assistência Básica (Secretaria Municipal, 2003), e busca estabelecer parâmetros para as relações entre o projeto de saúde mental e o BH-Vida, versão belorizontina da saúde da família. Seu contorno visa a atender à função de "apoio matricial" preconizada pelo Ministério da Saúde (Brasil, 2004), e seu diferencial em relação a outros documentos é sua redação conjunta entre a coordenação de saúde mental e as gerências de atenção à saúde, ainda que a linguagem e o ideário que ele apresenta tenham clara ligação com o MTSM.

Os princípios e diretrizes do Projeto de Saúde Mental são apresentados com a clareza conceitual própria da experiência de um projeto consolidado. Segundo o documento, 
trata-se, mais do que desospitalizar o paciente, de desmontar o manicômio ampliado, "instituição que engendrou um conjunto de dispositivos no plano da política, da cultura, do mundo do trabalho, da contratualidade e sociabilidade em geral, que excluem e segregam a loucura" (p. 2). Trata-se, essencialmente de uma desinstucionalização. Apesar de essa bandeira datar de 1987, existe um diferencial no documento em relação ao anterior: a busca de um avanço para além do trabalho na rede assistencial, na direção de maior inserção comunitária e social. Visa ao desenvolvimento de ações "que vão da assistência e da clínica às dimensões relativas à reabilitação/reinserção no mundo do trabalho, da cultura, da reprodução social ampla" (p. 2), e discute também a importância do atendimento na crise, evento que alimenta o sistema manicomial, sem a busca apressada da internação. Afinal, "não há provas de que serviços com alta densidade tecnológica e aparato médico-psiquiátrico sejam mais eficazes do que dispositivos e iniciativas mais leves, centrados no acolhimento, na escuta e na presença dos cuidadores". Finalmente, aponta o trabalho em equipe como instrumento para superação do paradigma médico, "alargando competências comuns, desmontando e reorganizando poderes e saberes estabelecidos" (p. 3).

No âmbito da integração das equipes de saúde mental (ESM) com as equipes de saúde da família (ESF), o documento preconiza que as primeiras "priorizarão o atendimento aos portadores de sofrimento mental grave e persistente, e as ESF se responsabilizarão pelas necessidades clínicas dessa clientela" (p. 4). As ESM continuariam acolhendo outras demandas mais leves, mas estas seriam atendidas pelas ESF, com o apoio das ESM. As ESM seriam compostas de um psiquiatra e dois técnicos superiores de saúde. Os usuários e familiares devem participar da formulação dos projetos terapêuticos e do controle e planejamento das ações de saúde mental.
No que tange à formação, o documento cita a “discussão conjunta dos casos entre ESM/ESF, como forma de intercambiar cotidianamente, no trabalho concreto, saberes e competências, bem como, progressivamente, ir delimitando a clientela" (p. 5).

Cinco anos depois da elaboração desse documento, a SMSA de Belo Horizonte publicou um livro contendo textos escritos por trabalhadores da rede do Município abordando diversos aspectos do Programa de Saúde Mental (Nilo et al., 2008). Um dos temas mais abordados é a precisamente a relação entre saúde mental e saúde da família, em um total de seis artigos. Nos títulos, as palavras parceria, integração e interface dão o tom dos textos que testemunham os impactos da trajetória inicial do apoio matricial nas práticas de saúde do Município.

\section{Alguns elementos de discussão}

A hegemonia da psicanálise como saber presente no setor, refletindo a ênfase dos cursos de graduação, é um fator que merece ser avaliado. Vale lembrar que a hegemonia da orientação psicanalítica na discussão das práticas clínicas em saúde mental ocorre em outras capitais brasileiras (Lima, 2005; Onocko Campos, 2001). Se, por um lado, importa reconhecer o caráter politicamente original que a psicanálise, de modo criativo, vem exercendo no contexto da saúde pública brasileira (Lobosque \& Abou-yd, 1998), fato reconhecido, inclusive, por autores estrangeiros: "em certos países (eu penso no Brasil), a psicanálise desempenhava um papel político positivo de denúncia da cumplicidade entre os psiquiatras e o poder", enquanto, na maioria dos lugares, ela exercia uma função normalizadora (Foucault, 1979, p. 150), por outro lado, essa presença maciça da psicanálise na saúde tem seus efeitos colaterais. A condição de psicanalista exerce 
"Nesse sentido, portanto, não há, em relação à psicanálise, a possibilidade de um conhecimento multidisciplinar", pois esta é apresentada pelos profissionais entrevistados como um saber completo autossuficiente, ainda que mantenha diálogo com disciplinas como a Filosofia, a Lingüística, etc. (Lo Bianco et al., 1994, p. 23). inegável atrativo de ideal de identidade, levando os profissionais a sobre-valorizarem, em sua atuação, ações compatíveis com esse modelo, ou seja, ações clínicas, e a se recusarem com isso a exercer outras importantes ações na saúde pública, por não serem suficientemente "psicanalíticas" (Lima, 2005). A pesquisa realizada pelo Conselho Federal de Psicologia em 1994 apontava uma tendência do trabalho multidisciplinar em várias áreas da clínica, exceção feita exatamente à psicanálise. "Nesse sentido, portanto, não há, em relação à psicanálise, a possibilidade de um conhecimento multidisciplinar", pois esta é apresentada pelos profissionais entrevistados como um saber completo autossuficiente, ainda que mantenha diálogo com disciplinas como a Filosofia, a Lingüística, etc. (Lo Bianco et al., 1994, p. 23). Na experiência de Belo Horizonte, atualmente encontramos um movimento, não desprovido de tensão, por parte da coordenação de saúde mental, de sinalizar a necessidade de um debate interdisciplinar no campo da saúde mental (Jornal Sirimim, 2004, p. 4), ainda que o discurso de grande parte dos profissionais nos serviços seja eminentemente norteado pela psicanálise (Ferreira Neto, 2008).

A experiência de Belo Horizonte na saúde mental no viés antimanicomial se encontra hoje em fase de consolidação, depois de desenvolver uma longa trajetória que envolveu, entre outras coisas, a implantação de uma política de atenção, uma organização dos serviços, enfim, a construção da rede assistencial coordenada. Não foi suficiente, portanto, a simples lotação de profissionais em unidades de saúde para que o projeto de saúde mental efetivamente acontecesse. O fluxo histórico dos pacientes com transtornos severos e persistentes corre na direção do hospital psiquiátrico, e sua reversão demandou a construção de uma rede assistencial, de fato, resolutiva, que exigiu um conjunto de esforços para sua efetivação. O mesmo ainda não ocorreu em outros Municípios brasileiros, como é o caso de Salvador, conforme o relato da pesquisa de Lima (2005). Dessa forma, lá encontramos uma ociosidade do profissional que atua exclusivamente na atenção clínica do paciente grave, e, em consequência, maior espaço para atuação em outros programas da saúde em geral. Esse não é o caso de Belo Horizonte atualmente e de uma série de outros Municípios. Uma pesquisa realizada com profissionais psicólogos em um distrito sanitário dessa cidade aponta, na verdade, uma demanda excessiva no trabalho de atendimento e manejo das articulações da rede assistencial, inclusive na integração com as ESF (Ferreira Neto, 2008). O mesmo ocorre em outros Municípios com o mesmo perfil de organização da rede assistencial. Segundo Barros, existe uma "sobrecarga de trabalho entre os profissionais" na saúde mental (2003, p. 205).

Podemos hoje afirmar que as práticas assistenciais em saúde mental contribuíram, em muito, para a construção de novas referências clínicas diferentes do modelo clássico (Ferreira Neto, 2008; Lo Bianco et al., 1994). Existem práticas clínicas na saúde mental que se afastam do modelo clássico de consultório gestadas no campo da saúde pública, e que trazem importantes contribuições para a discussão sobre o campo da Psicologia clínica no Brasil. Isso permitiu aos psicólogos o desenvolvimento de novas competências e habilidades clínicas no tratamento de pacientes graves, prática a que, em geral, não tiveram acesso em sua formação nas clínicas-escola universitárias. Em vários contextos, a saúde mental rompeu o modelo de uma clínica alicerçada no atendimento individual, para incluir em seu campo o trabalho em equipe, as interfaces interinstitucionais e a aliança com recursos da comunidade, que tem trazido contribuições inclusive para a formação universitária em 
Psicologia. Tal fato ocasionou a tendência de requalificar a expressão clínica, sendo que a que mais se estabeleceu foi a de clínica ampliada, que inclusive passou a ser utilizada, a partir de uma redefinição, no campo da saúde coletiva (Campos, 2003). Entretanto, essa contribuição tem sido pouco discutida em grande parte da literatura que este trabalho explorou sobre a formação em Psicologia e o campo da saúde.

Nessa direção, poderíamos perguntar se haveria lugar para uma dupla atuação - programa de saúde mental e outros programas na saúde pública - em Municípios onde o projeto está consolidado e a pressão da demanda e do serviço se apresenta intensa. De fato, é em Municípios onde profissionais psicólogos estão lotados com certa ociosidade na atenção à clientela grave, em decorrência da não consolidação da rede assistencial, que ocorrem interessantes experiências de ações de saúde coletiva (Lima, 2005) ou ainda em projetos de alunos de extensão universitária localizados (Souza \& Carvalho, 2003). Seria difícil esperar, por parte de profissionais inseridos em programas consolidados, o exercício dessa dupla atuação, face à diversidade de ações clínicas e extraclínicas que a atuação em saúde mental exige, em uma conjuntura de demanda crescente e de contratação decrescente de novos quadros. Por essa razão, geralmente, sua atuação nos outros programas nas unidades é, em geral, esporádica. A recente aprovação da portaria que estabelece os Núcleos de Apoio à Saúde da Família (NASF), fortalecendo as ações de apoio matricial, aponta outras possibilidades de mudança dessa questão. Preconiza a criação de núcleos multiprofissionais, em composição escolhida entre 13 opções profissionais, com ênfase nas ações de planejamento, educação continuada, promoção da saúde e atendimento de casos. Recomenda também a presença de "pelo menos 1 profissional de saúde mental" em cada NASF (Brasil, 2008, p. 39). No caso da saúde mental, deve-se priorizar as "abordagens coletivas". Temos, portanto, uma sinalização clara do ensejo de fortalecer outras formas de intervenção além da prática clínica, convocando o conjunto dos profissionais da saúde, inclusive os psicólogos.

\section{Considerações finais}

Os impasses na atuação dos psicólogos na saúde pública surgem na confluência de diversos vetores, dos quais dois foram destacados e discutidos por este trabalho. O primeiro seria a tradição da formação em Psicologia no Brasil calcada em um modelo clássico de clínica, liberal, privada, curativa e individual, inspirado na clínica médica; o segundo, a porta de entrada preferencial dos profissionais contratados na rede pública na saúde mental, na esteira do movimento da reforma psiquiátrica. Como vimos, essa dupla ocorrência gerou sintomas inibidores no trabalho, em que as ações profissionais tendiam a reforçar um modelo de identidade clássico e individualista, ao invés de uma inserção mais inventiva no conjunto da saúde.

A progressiva e permanente transformação do SUS e a prática requerida aos psicólogos nesse setor permitiram significativos avanços no desenvolvimento de uma atuação mais pertinente e resolutiva por parte dos psicólogos; entretanto, como mostra parte da literatura recente, ainda há muito a ser revisto. Temos um cenário que aponta a importância da ampliação das ações no trabalho dos psicólogos na saúde mental, ampliando não somente a clínica mas também as intervenções extraclínicas. Nessa direção, vale ressaltar o impacto da implantação da saúde da família como principal estratégia para reorientação do modelo assistencial de atenção à saúde (Brasil, 2004a). Entre outros resultados, essa estratégia tem se mostrado um elemento promotor de integração entre a atuação específica das 
equipes de saúde mental e as ações das equipes de saúde da família. A ligação entre as ESF e as ESM no apoio matricial tem permitido uma integração ampliada das ações de saúde mental e de saúde geral, cujos efeitos ainda estão por ser adequadamente avaliados em pesquisas futuras.

\section{João Leite Ferreira Neto}

Doutor em Psicologia. Professor do Programa de Pós-Graduação em Psicologia da Pontifícia Universidade Católica de Minas Gerais, Belo Horizonte, MG - Brasil.

\section{Endereço para envio de correspondência:}

Rua Planetóides, 271/102 Bairro Santa Lúcia - Belo Horizonte, MG - Brasil - CEP 30360-440.

E-mail: jleite.bhe@terra.com.br

Recebido 20/5/2009, 1a Reformulação 15/8/2009, Aprovado 12/9/2009. 


\section{Referências}

Amarante, P. (Ed). (1998). Loucos pela vida: a trajetória da reforma psiquiátrica no Brasil (2a ed.). Rio de Janeiro: Fiocruz.

Barros, R. B. (2003). Reforma psiquiátrica brasileira: resistências e capturas em tempos neoliberais. In Conselho Federal e Psicologia (Ed.), Loucura, ética e política: escritos militantes (pp. 196-206). São Paulo: Casa do Psicólogo.

Bezerra Jr. (1994). De médico e louco cada um tem um pouco: o campo psiquiátrico no Brasil nos anos oitenta. In R. Guimarães \& A. W. Tavares (Eds.), Saúde e sociedade no Brasil: anos 80 (pp. 171-191). Rio de Janeiro: Relume Dumará.

Brasil. Ministério da Saúde. (2004a). Atenção básica e a saúde da família. Recuperado em 20 de fevereiro de 2006, de http:// dtr2004.saude.gov.br/dab/atencaobasica.php

Brasil. Ministério da Saúde. (2004b). Saúde mental no SUS: os centros de atenção psicossocial. Recuperado em 20 de fevereiro de 2006, de http://www.ccs.saude.gov.br/ saude_mental/pdf/SM_Sus.pdf

Brasil. Ministério da Saúde. (2008). Portaria no. 154, de 24 de janeiro de 2008 - Cria Núcleos de Apoio à Saúde da Família. Diário Oficial da União, (43), pp. 38-42.

Campos, G. S. W. (2003). Saúde paidéia. São Paulo: Hucitec.

Dimenstein, M. D. (1998). O psicólogo nas unidades básicas de saúde: desafios para a formação e atuação profissionais. Estudos de Psicologia, 3(1), 53-81.

Dimenstein, M. D. (2001). O psicólogo e o compromisso social no contexto da saúde coletiva. Psicologia em Estudo, 6(2), 57-63.

Ferreira Neto, J. L. (2004). A formação do psicólogo: clínica, social e mercado. São Paulo: Escuta.

Ferreira Neto, J. L. (2008). Práticas transversalidadas da clínica em saúde mental. Psicologia: Reflexão e Crítica, 21(1), 110-118.

Foucault, M. (1979). Microfísica do poder (R. Machado, trad.). Rio de Janeiro: Graal.

Furtado, J. P., \& Onocko Campos, R. (2005). A transposição das políticas de saúde mental no Brasil para a prática nos novos serviços. Revista Latino Americana de Psicopatologia Fundamental, 8(1), 109-122.

Jornal Sirimim, 3(3). (2004, agosto/dezembro). Belo Horizonte: Secretaria Municipal de Saúde.

Jornal Sirimim, 4(1). (2005, janeiro/abril). Belo Horizonte: Secretaria Municipal de Saúde.
Lima, M. (2005). Atuação psicológica coletiva: uma trajetória profissional em unidade básica de saúde. Psicologia em Estudo, 10(3), 431-440.

Lo Bianco, A. C., Bastos, A. V., Nunes, M. L., \& Silva, R. C. (1994) Concepções e atividades emergentes na psicologia clínica: implicações para a formação. In R. Achar, Psicólogo brasileiro: práticas emergentes e desafios para a formação (pp. 7-79) São Paulo: Casa do Psicólogo.

Lobosque A. M., \& Abou-Yd, M. (1998). A cidade e a loucura: entrelaces. In A. Reis et al. (Eds.), Sistema Único de Saúde em Belo Horizonte: reescrevendo o público (pp. 243-264). São Paulo: Xamã.

Mendonça Filho, J. B., \& Alkimin, W. (1998). A saúde mental no município de Belo Horizonte: prática em saúde mental nos centros de saúde. Mimeo.

Nilo, K., Morais, M. A., Guimarães, M. B., Vasconcelos, M. Nogueira, M. T., \& Abou-Yd, M. (2008). Política de saúde mental de Belo Horizonte: o cotidiano de uma utopia. Belo Horizonte: Secretaria Municipal de Belo Horizonte.

Onocko Campos, R. (2001). Clínica: a palavra negada - sobre as práticas clínicas nos serviços substitutivos de saúde mental. Saúde em Debate, 25(58), 98-111.

Secretaria Estadual de Saúde de Minas Gerais. (1985). Programa de ações em saúde mental. Região Metropolitana de Belo Horizonte. Belo Horizonte: Autor.

Secretaria Municipal de Saúde de Belo Horizonte. Grupo de trabalho Geas/integração Saúde Mental e Saúde da Família. (2003). Saúde mental na assistência básica. Belo Horizonte: Autor.

Secretaria Municipal de Saúde de Belo Horizonte. Coordenação de Saúde Mental. (n.d.). 1993-2003 - projeto de saúde mental de Belo Horizonte - 10 anos de luta! Belo Horizonte: Autor

Silva, R. C. (1992). A formação em psicologia para o trabalho na saúde pública. In F. C. B. Campos (Ed.), Psicologia e saúde: repensando práticas (pp. 25-40). São Paulo: Hucitec.

Spink, M. J. (2003). Psicologia social e saúde: práticas, saberes e sentidos. Petrópolis, RJ: Vozes.

Spink, M. J. (Ed.). (2007). A psicologia em diálogo com o SUS: prática profissional e produção acadêmica. São Paulo: Casa do Psicólogo.

Souza, R. A., \& Carvalho, A. M. (2003). Programa de saúde da família e qualidade de vida: um olhar da psicologia. In Estudos de Psicologia, 8(3), 515-523. 